\title{
Speciation of Heptavalent Technetium in Sulfuric Acid: Structural and Spectroscopic Studies.
}

Frederic Poineau, ${ }^{\mathrm{a}}$, Philippe F. Weck, Konstantin German, Alesya Maruk, Gayane Kirakosyan, Wayne Lukens(Chemical Sciences Division. Lawrence Berkeley National Laboratory, Berkeley, CA 94720), Daniel B. Rego, Alfred P. Sattelberger, Kenneth R. Czerwinski

Summary. The speciation of Tc(VII) in $12 \mathrm{M}$ sulfuric acid was studied by NMR, UVvisible and XAFS spectroscopy, experimental results were supported by DFT calculation and were in agreement with the formation of $\mathrm{TcO}_{3} \mathrm{OH}\left(\mathrm{H}_{2} \mathrm{O}\right)_{2}$.

Heptavalent transition metal complexes of group VII with the $\mathrm{d}^{0}$ electronic configuration are often used in catalysis and biomedical applications. [1, 2, 3] For manganese, the high electron affinity and oxidation potential of its heptavalent complexes make these species the catalysts of choice for oxidation of organic compounds.[4] The chemistry of Re(VII) complexes has been extensively studied, and species with the $\mathrm{ReO}_{3}{ }^{+}$core (e.g., $\mathrm{CH}_{3} \mathrm{ReO}_{3}$ ) have been reported to be efficient catalysts.[3] Concerning technetium, its coordination chemistry has mainly been driven by radiopharmaceutical applications. Pentavalent and trivalent Tc complexes have been the most studied while heptavalent coordination complexes are still rare.[5] Permetallates with the tetrahedral geometry are the most common heptavalent species and are stable in aqueous media over a large range of $\mathrm{pH}$ and electrochemical potential.[6] In concentrated acid, permetallates are generally unstable and reduction, dimerisation, dehydration or complexation can occur.[7, 8, 9,10] The reaction of pertechnetate in water with strong acid leads to dehydration and various complexes with $\mathrm{TcO}_{3}{ }^{+}$core have been synthesized.[11] In theses synthetic reactions, it is assumed that the anhydrous $\mathrm{Tc}_{2} \mathrm{O}_{7}$ is formed as an intermediate product.[11]

Sulfuric acid is widely used in industrial applications; it is also a solvent of choice for dehydration process. [12-13] Speciation of $\mathrm{Mn}(\mathrm{VII})$ in $\mathrm{H}_{2} \mathrm{SO}_{4}$ has been documented; manganese heptoxide is formed after dissolution of $\mathrm{KMnO}_{4}$ and the $\mathrm{MnO}_{3}{ }^{+}$cation has been reported. $[14,15,16]$. For technetium and rhenium, speciation data are still sparse, the $\mathrm{HReO}_{2}\left(\mathrm{SO}_{4}\right)_{2} .3 \mathrm{H}_{2} \mathrm{O}$ complex has been mentioned while technetium heptoxide has been proposed but no structural nor speciation data were provided. [17-18] In the present work, the speciation of technetium complexes after dissolution of $\mathrm{KTcO}_{4}$ in sulfuric acid has been performed. The molecular structure and spectroscopic properties of the complexes were studied by UV-visible, X-ray absorption fine structure (XAFS) and NMR spectroscopy and density functional theory (DFT) techniques.

Potassium pertechnetate ( $30 \mathrm{mg}$ ) was placed in glass vials, and $1 \mathrm{M}, 6 \mathrm{M}, 12 \mathrm{M}$ sulfuric acid $(5 \mathrm{~mL})$ was added with a glass pipette. After dissolution of the salt, a yellow color is observed in $12 \mathrm{M}$ while for $1 \mathrm{M}$ and $6 \mathrm{M}$, the solution remains clear. UV-visible spectroscopy measurements in $1 \mathrm{M}$ and $6 \mathrm{M}$ show the presence of $\mathrm{TcO}_{4}{ }^{-}$while in $12 \mathrm{M}$, the spectrum of the yellow solution differs from that of the pertechenate (vide supra). The conditions of formation of the yellow species were investigated by NMR spectroscopy. Technetium samples were prepared in $\mathrm{H}_{2} \mathrm{SO}_{4}$ (from $3 \mathrm{M}$ to $18 \mathrm{M}$ ) and ${ }^{99} \mathrm{Tc}$ NMR spectra 
were recorded. The representation of the ${ }^{99} \mathrm{Tc}$ chemical shift vs $\mathrm{TcO}_{4}^{-}$(Figure 1) indicates that the formation of the new species is noticeable at $8 \mathrm{M}$ and is complete at $\sim 12 \mathrm{M}$ $\mathrm{H}_{2} \mathrm{SO}_{4}$. In this domain of concentration, the dissociation of sulfuric acid produces mainly $\mathrm{HSO}_{4}{ }^{-}$and $\mathrm{H}_{3} \mathrm{O}^{+}$.[19] Therefore, it is likely that an acid-base phenomenon is responsible for the formation of the yellow species.

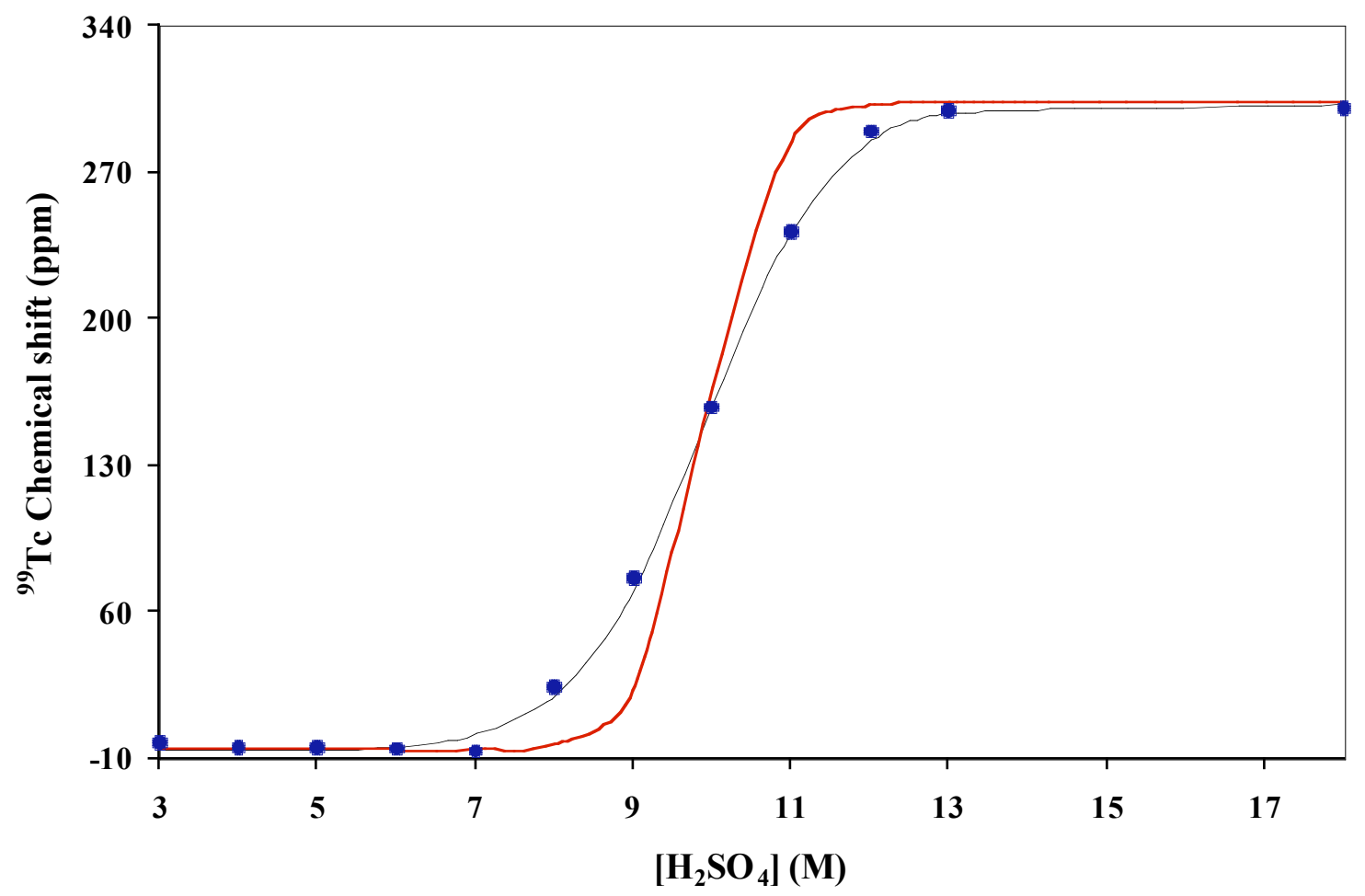

Figure 1. ${ }^{99} \mathrm{Tc}$ NMR shift vs $\mathrm{TcO}_{4}{ }^{-}$of $\mathrm{KTcO}_{4}$ dissolvd in $3 \mathrm{M}$ and $18 \mathrm{M} \mathrm{H}_{2} \mathrm{SO}_{4}$. Data are externally referenced to $0.05 \mathrm{M} \mathrm{KTcO}_{4}$ in water. Experimental data are indicated by points, black line is the chemical shift fit using eq 1, and the red line chemical shift fit using eq 2 .

The chemical shift of the protonated species is a function of the coordination environment of Tc. Previous ${ }^{99}$ Tc NMR studies have shown that the shift of Tc(VII) complexes varies between 0 and $430 \mathrm{ppm}$. [20, 21, 22a-d] In the present experiment, the shift measured in $12 \mathrm{M}(300 \mathrm{ppm})$ is consistent with the presence of a heptavalent species. The value of the shift depends of the core structure. For complexes with the $\mathrm{TcO}_{3}{ }^{+}$core, the shift varies between $43.7 \mathrm{ppm}$ and $375 \mathrm{ppm}$, for compounds with the $\mathrm{TcO}_{2}{ }^{3+}$ core, a shift between $140 \mathrm{ppm}$ and $393 \mathrm{ppm}$ has been reported. The chemical shift of $\mathrm{Tc}_{2} \mathrm{O}_{7} \cdot \mathrm{H}_{2} \mathrm{O}$ has been reported to be $\sim 10 \mathrm{ppm}$.[23] The chemical shift of the yellow Tc species, $300 \mathrm{ppm}$, is most similar to those of $\left\{\mathrm{CpCo}\left[\mathrm{PO}\left(\mathrm{OEt}_{2}\right)\right]_{3}\right\} \mathrm{TcO}_{3}$ and $(\operatorname{tacn}) \mathrm{TcO}_{3} \mathrm{Cl}$. [24a- 24b] This similarity suggests that the yellow Tc complex may possess the $\mathrm{TcO}_{3}{ }^{+}$ core structure resulting from single protonation (" $\mathrm{HTcO}_{4}$ ") or double protonation (" $\mathrm{TcO}_{3}\left(\mathrm{H}_{2} \mathrm{O}\right)^{+}$") of $\mathrm{TcO}_{4}{ }^{-}$. 
To determine the stoichiometry of the reaction, the chemical shift of the Tc species was modeled using a simple equilibria, give by eq 1 and 2 , and the Hammett acidity, $\mathrm{H}_{0}$, of sulfuric acid.[25]

$\log \left(\left[\mathrm{HTcO}_{4}\right] /\left[\mathrm{TcO}_{4}^{-}\right]\right)=\mathrm{pK}_{\mathrm{HTcO} 4}-\mathrm{H}_{0} \quad$ eq 1 .

$\log \left(\left[\mathrm{TcO}_{3}\left(\mathrm{H}_{2} \mathrm{O}\right)^{+}\right] /\left[\mathrm{TcO}_{4}^{-}\right]\right)=\mathrm{pK}_{\mathrm{TcO} 3\left(\mathrm{H} 2 \mathrm{O}^{+}\right.}-2 \mathrm{H}_{0} \quad$ eq 2 .

The ${ }^{99} \mathrm{Tc}$ NMR data were fit by allowing the $\mathrm{pK}_{\mathrm{a}} \mathrm{s}$ and the chemical shifts of the unprotonated and protonated species to vary. The best fit was provided by eq with $\delta=-$ $5.8 \mathrm{ppm}$ for $\mathrm{TcO}_{4}{ }^{\prime}, \delta=303 \mathrm{ppm}$ for " $\mathrm{HTcO}_{4}$ ", and $\mathrm{pK}_{\mathrm{HTcO} 4}=-4.9$ (the chemical shift of $\mathrm{TcO}_{4}{ }^{-}$differs from 0 because the spectra were externally referenced)..As shown in Figure 1 , eq 1 fits the data while eq 2 does not.. The value of $\mathrm{pK}_{\mathrm{HTCO} 4}$ is different with values of $\mathrm{pK}_{\mathrm{HTCO} 4}$ determined by solvent extraction and ion exchange.[26] However, this value for $\mathrm{pK}_{\mathrm{HTCO} 4}$ is consistent with previous spectroscopic studies that report no appreciable formation of $\mathrm{HTcO}_{4}$ when $\left[\mathrm{H}^{+}\right]$is less than $7 \mathrm{M}$. $[18,27]$

To better understand the molecular structure of the yellow species, $\mathrm{X}$-ray absorption fine structure measurements were performed. A solution of $\mathrm{KTcO}_{4}(0.01 \mathrm{M})$ in $12 \mathrm{M} \mathrm{H}_{2} \mathrm{SO}_{4}$ was prepared and shipped to the Advanced Photon Source for XAFS measurement. (Details about measurement are provided in supporting information) The x-ray absorption near edge spectrum (XANES) is given in the supplemental information (Figure S1). The energy of the absorption edge $(21058.2 \mathrm{eV})$ is consistent with $\mathrm{Tc}(\mathrm{VII})$ and spectra exhibits a pre-edge feature which correspond to the $1 \mathrm{~s} \rightarrow 4 \mathrm{~d}$ electronic transition. This transition is forbidden in complex with inversion symmetry and indicates that the species under investigation does not exhibit an inversion center.

The extended $\mathrm{x}$-ray absorption fine structure (EXAFS) spectrum was $\mathrm{k}^{3}$-weighed and Fourier transform (FT) done in the $\mathrm{k}$ range [2-12] $\AA^{-1}$. The FT shows one peak centered at $\mathrm{R}+\Delta \sim 1.4 \AA$, which is at the same position as in $\mathrm{TcO}_{4}{ }^{-}$and indicates the yellow species possesses $\mathrm{Tc}=\mathrm{O}$ bonds. Further analysis of the FT indicates the absence of significant peaks above $2.5 \AA$, thus eliminating the possibility of $\mathrm{Tc}_{2} \mathrm{O}_{7}$ and Tc sulfatocomplexes. Simulated Fourier transform of $\mathrm{Tc}_{2} \mathrm{O}_{7}$ and $\mathrm{TcO}_{2}\left(\mathrm{SO}_{4}\right)_{3}{ }^{3-}$ complexes (Figure $\mathrm{S} 2$ and $\mathrm{S} 3$ in supporting information) exhibit respectively a significant peak around $3.2 \AA$ due to $\mathrm{Tc} \leftrightarrows \mathrm{Tc}$ scattering and around $2.8 \AA$ due to $\mathrm{Tc} \leftrightarrows \mathrm{S}$ scattering.

To determinate the geometry of the complex, various models with short oxygen and long oxygen distances were tested (supplemental information). The best models all have three short Tc terminal oxo bonds. The parameters for the best fit are given in Table 1, and the EXAFS spectrum and fit are shown in Figure 2. 


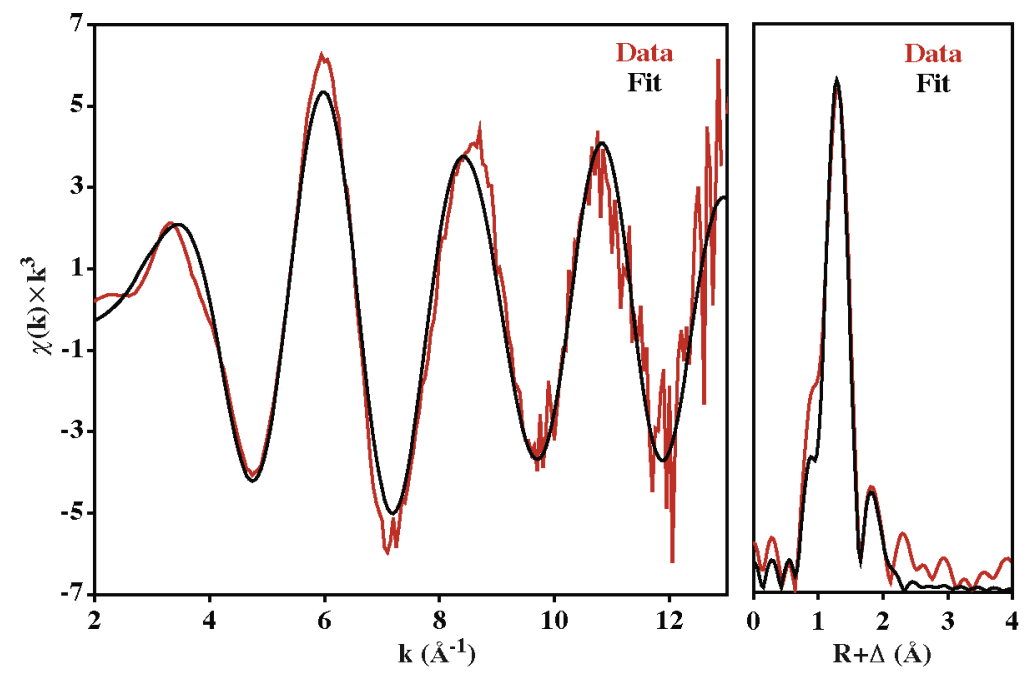

Figure 2. Fitted $\mathrm{k}^{3}$ EXAFS spectra and Fourier transform of $\mathrm{k}^{3}$ EXAFS spectra of $\mathrm{KTcO}_{4}$ in $12 \mathrm{M} \mathrm{H}_{2} \mathrm{SO}_{4}$. Data is show in red and the fit is shown in black

Table 1: EXAFS fit parameters for $\mathrm{KTcO}_{4}$ in $12 \mathrm{M} \mathrm{H}_{2} \mathrm{SO}_{4}{ }^{\mathrm{a}}$

\begin{tabular}{ccccc}
\hline Neighbor & \# of Neighbors & Distance $(\AA)$ & $\sigma 2(\AA 2)$ & $\mathrm{p}(\mathrm{F})^{\mathrm{b}}$ \\
\hline$O$ & 3 & $1.702(8)$ & $0.0022(4)$ & $<0.001$ \\
$O$ & 1 & $2.07(4)$ & $0.004(4)$ & 0.14 \\
$O$ & 2 & $2.23(3)$ & $0.004(4)^{\mathrm{c}}$ & 0.048 \\
\hline
\end{tabular}

a) $2<\mathrm{k}<12,0.8<\mathrm{R}<3, \mathrm{r}=0.009, \chi_{\mathrm{v}}{ }^{2}=24, \mathrm{~S}_{0}{ }^{2}=0.9$ (fixed), $\Delta \mathrm{E}_{0}=-1(3) \mathrm{eV}$

b) Probability that improvement in fit due to adding this shell is due to random error.

c) Debye-Waller parameter was constrained to equal that of the previous shell

The model used to fit the EXAFS spectrum is based on the structure of perrhenic acid, $\mathrm{Re}_{2} \mathrm{O}_{7}\left(\mathrm{H}_{2} \mathrm{O}\right)_{2}$, which is an asymmetric dimer consisting of a tetrahedral Re with three terminal oxo ligands joined by a bridging oxo to a distorted octahedral Re with three terminal oxo ligands and two water ligands. [28] The six coordinate Re center was used as the model complex by replacing the tetrahedral Re moiety by a proton. The parameters for the best fit, given in Table 1, are very similar to the model complex. It should be noted that although the Tc-O interaction at $2.07 \AA$ improves the fit, its $\mathrm{p}(\mathrm{F})$ is 0.14 , and this interaction cannot rigorously be considered observed in the EXAFS experiment (there is a $14 \%$ chance that the improvement due to including this scattering shell is due to random error). In contrast, the other Tc-O interactions have $\mathrm{p}(\mathrm{F})<0.05$ and can be considered to be observed in the EXAFS experiment. The EXAFS fit shows $3 \mathrm{Tc}=\mathrm{O}$ groups at $1.70 \AA$, in good agreement with the three $\mathrm{Re}=\mathrm{O}$ groups at $1.74 \AA$; one Tc-O at $2.07 \AA$, which is similar to the Re-bringing oxide distance of $2.10 \AA$. Finally the longest Tc-O distance of $2.23 \AA$ is similar to the $\mathrm{Re}-\left(\mathrm{H}_{2} \mathrm{O}\right)$ distance, $2.18 \AA$. Moreover, the ligand most likely responsible for this Tc-O interaction is water since a coordinated sulfate ligand should have a scattering contribution at longer distances as described above. 
Overall, the EXAFS spectrum of the yellow species is consistent with $\mathrm{TcO}_{3}(\mathrm{OH})\left(\mathrm{H}_{2} \mathrm{O}\right)_{2}$, which can also be described as $\mathrm{HTcO}_{4}$ coordinated by two $\mathrm{H}_{2} \mathrm{O}$ molecule. This proposed 6-coordinate structure is quite similar the previously mentioned 6-coordinate $\mathrm{TcO}_{3}{ }^{+}$ complexes as well as $\left[\mathrm{TcO}_{3}\right]\left[\mathrm{SO}_{3} \mathrm{~F}\right]$ where the Tc terminal oxo bond distances vary from $1.68 \AA$ to $1.72 \AA$ and the distance to the longer nitrogen or oxygen ligands varies from $2.15 \AA$ to $2.24 \AA$. [29]

To better define the identity of " $\mathrm{HTcO}_{4}$ " in $12 \mathrm{M} \mathrm{H}_{2} \mathrm{SO}_{4}$, a search for the possible structures was carried out using DFT calculations within the generalized gradient approximation (GGA) and with the Becke 3-parameter, Lee, Yang and Parr (B3LYP) hybrid functional (details in supplemental information). The computed equilibrium geometry of the $\mathrm{TcO}_{3}(\mathrm{OH})\left(\mathrm{H}_{2} \mathrm{O}\right)_{2}$ complex with $C_{\mathrm{s}}$ symmetry depicted in Figure 3 closely matches structural parameters previously found by XAFS spectroscopy. This complex possesses three short $\mathrm{Tc}=\mathrm{O}$ bonds (two $\mathrm{Tc}=\mathrm{O}$ bonds of $1.72 \AA$ and one $\mathrm{Tc}=\mathrm{O}$ bond of $1.74 \AA$ ), and three Tc-O bonds (two Tc- $\mathrm{OH}_{2}$ bonds of $2.31 \AA$ and one Tc-OH bond of $2.02 \AA$ ).
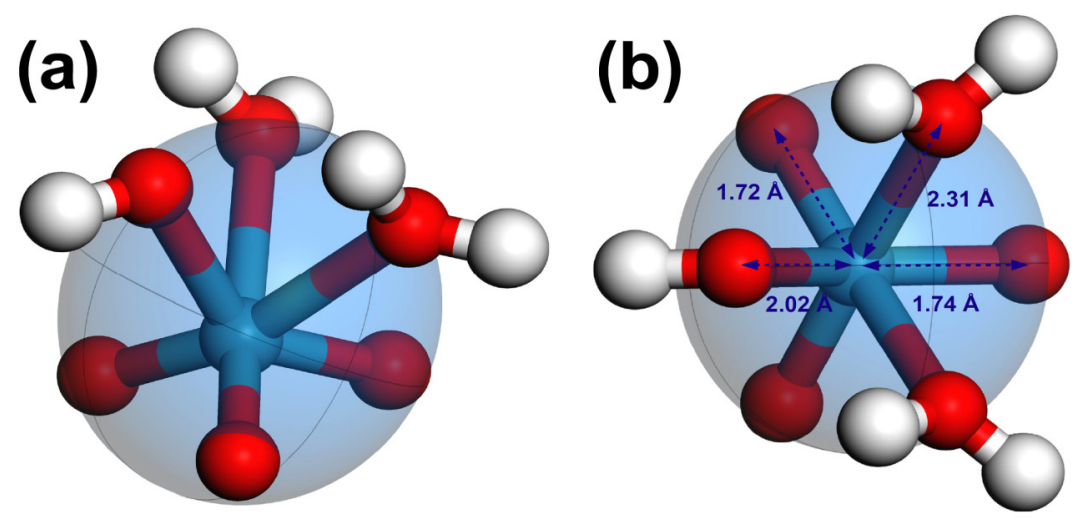

Figure 3. Equilibrium structure of the $\mathrm{TcO}_{3}(\mathrm{OH})\left(\mathrm{H}_{2} \mathrm{O}\right)_{2}$ complex with $C_{\mathrm{s}}$ symmetry calculated using DFT at the B3LYP/SSD level of theory. (a) Side view, (b) top view. Color legend: Tc, cyan; O, red; $\mathrm{H}$, white.

The electronic structure of $\mathrm{TcO}_{3}(\mathrm{OH})\left(\mathrm{H}_{2} \mathrm{O}\right)_{2}$ reflects the $C_{\mathrm{s}}$ symmetry of this complex, with non-degenerate MOs belonging either to the $A^{\prime}$ or $A^{\prime \prime}$ representations of this point group. The calculated HOMO-LUMO energy gap is $4.56 \mathrm{eV}$, slightly smaller than the one of $\mathrm{TcO}_{4}{ }^{-}(5.16 \mathrm{eV})$ but significantly larger than the gap of 6-coordinate $\mathrm{Tc}$ complexes (e.g., $\sim 1.2 \mathrm{eV}$ for $\mathrm{TcX}_{6}^{2-}(\mathrm{X}=\mathrm{Cl}, \mathrm{Br})$. [30] The highest-occupied MOs ranging from the HOMO to the HOMO-7 are ligand-localized (cf. Figure 4), and are mainly derived from the $\mathrm{O} 2 p$ orbitals of the $\mathrm{TcO}_{3}{ }^{+}$core or OH ligand (HOMO to HOMO-5), and of the $\mathrm{H}_{2} \mathrm{O}$ ligands (HOMO-6 and HOMO-7). The lower-lying HOMO-8 orbital shows a significant contribution from the Tc $4 d$ orbitals in addition to the $\mathrm{O} 2 p$ orbitals of the core and the $\mathrm{OH}$ ligand. The lowest-lying unoccupied MOs of the complex are based almost exclusively on the $\mathrm{TcO}_{3}{ }^{+}$core (LUMO), with the presence of unoccupied $\mathrm{O} 2 p$ and Tc $4 d$ orbitals, and some modest $\mathrm{O} 2 p$ contribution from the $\mathrm{OH}$ ligand (LUMO+1 and LUMO+2). These low-lying unoccupied $d$ orbitals of the $\mathrm{TcO}_{3}{ }^{+}$ion favor ligand-to-metal charge transfer (LMCT), i.e. O $2 p \rightarrow$ Tc $4 d$ transitions. 


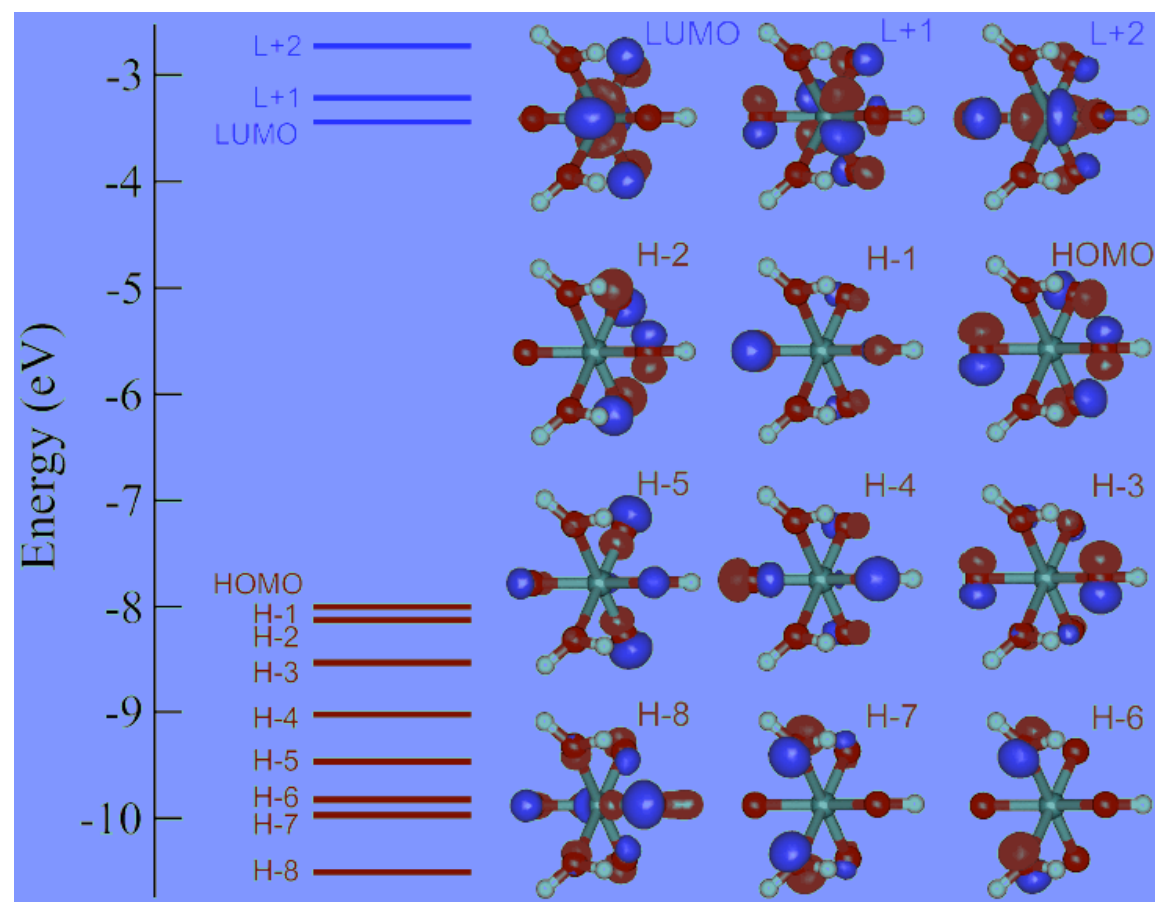

Figure 4. Energy diagram of the highest-lying molecular orbitals (MO) of the $C_{\mathrm{s}^{-}}$ symmetry $\mathrm{TcO}_{3}(\mathrm{OH})\left(\mathrm{H}_{2} \mathrm{O}\right)_{2}$ complex computed at the B3LYP/SDD level of theory. Occupied and unoccupied energy levels are represented in red and blue, respectively. The MOs involved in the major LMCT bands are also represented.

The spectroscopic properties of the yellow species were analyzed in $12 \mathrm{M} \mathrm{H}_{2} \mathrm{SO}_{4}$ by UVvisible spectroscopy. Its electronic spectrum (Figure 5) is different from that of $\mathrm{TcO}_{4}{ }^{-}$; it exhibits a distinct band at $335 \mathrm{~nm}$, a shoulder at $270 \mathrm{~nm}$ and a series of bands in the vicinity $250 \mathrm{~nm}-200 \mathrm{~nm}$. The valence of the complex was further confirmed after dilution of yellow solution with water; the UV-visible spectrumt of the diluted the is identical to that of $\mathrm{TcO}_{4}{ }^{-}$. Moreover, the yellow species is unlikely to be be $\mathrm{Tc}(\mathrm{IV})$, $\mathrm{Tc}(\mathrm{V})$, or $\mathrm{Tc}(\mathrm{VI})$, since in water, Tc(IV) complexes exhibit characteristic spectra, and $\mathrm{Tc}(\mathrm{V})$ and $\mathrm{Tc}(\mathrm{VI})$ species disproportionate to $\mathrm{Tc}(\mathrm{IV}) \cdot[31,26]$

Excitation energies and oscillator strengths for the lowest-lying excited states of the $\mathrm{TcO}_{3}(\mathrm{OH})\left(\mathrm{H}_{2} \mathrm{O}\right)_{2}$ complex were computed using the time-dependent density functional theory (TD-DFT) at the GGA/B3LYP level of theory. Theoretical results are reported in Figure 5 along with the experimental spectrum (cf. Table S2 for numerical values). 


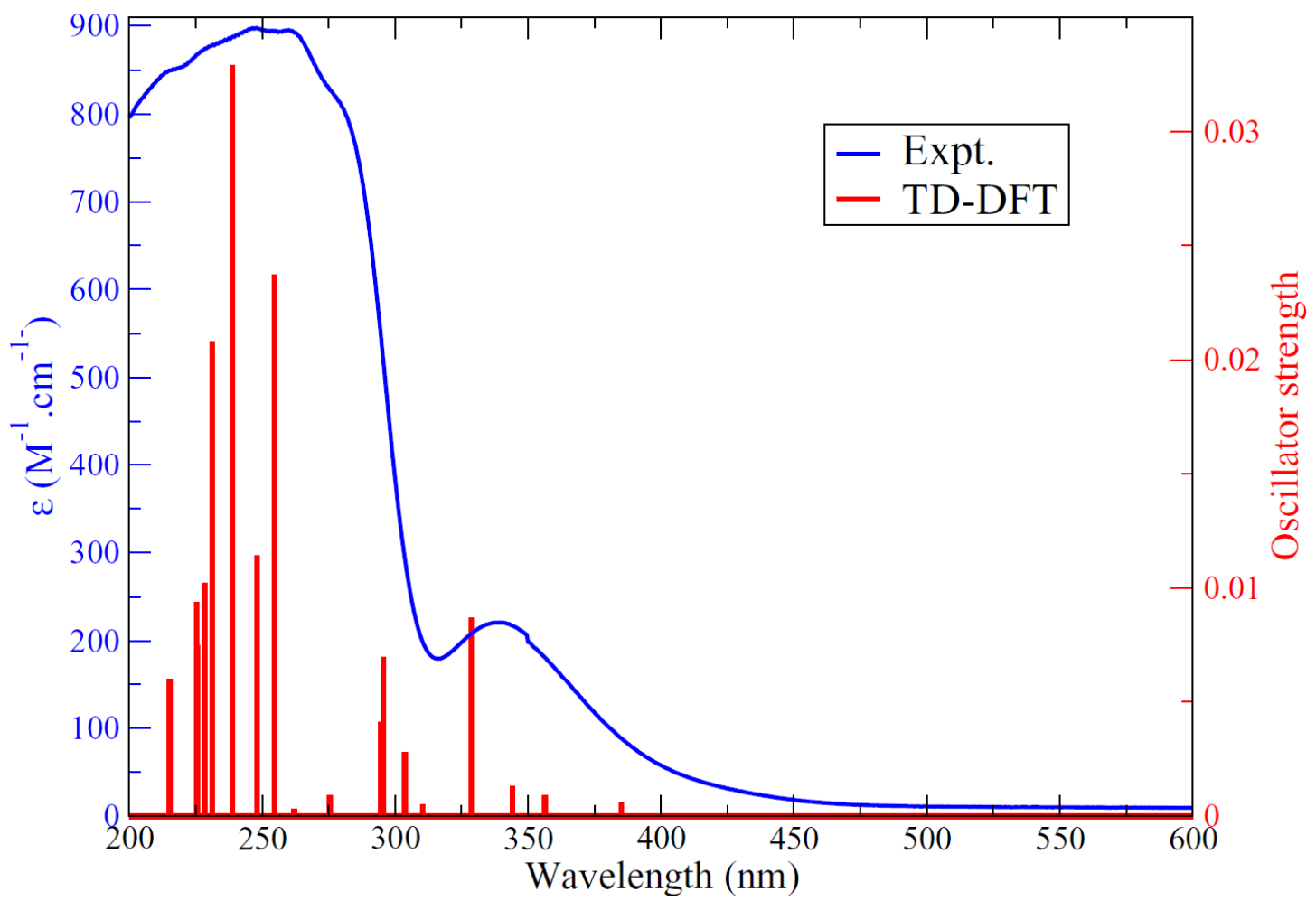

Figure 5. Experimental UV-Visible spectrum of $\mathrm{KTcO}_{4}$ in $12 \mathrm{M} \mathrm{H}_{2} \mathrm{SO}_{4}$ (blue) and oscillator strengths for the $C_{\mathrm{s}}$-symmetry $\mathrm{TcO}_{3}(\mathrm{OH})\left(\mathrm{H}_{2} \mathrm{O}\right)_{2}$ complex calculated using TDDFT at the B3LYP/SSD level of theory (red).

The major bands for the lowest-lying excited states of $\mathrm{TcO}_{3}(\mathrm{OH})\left(\mathrm{H}_{2} \mathrm{O}\right)_{2}$ are computed to be at 329, 295, 255, 248, 239, 231, 228, 225 and $215 \mathrm{~nm}$. For most of the bands, calculations show a combination of one-electron transitions from occupied $\mathrm{O}$ ligandbased MOs into the virtual Tc metal-localized MOs. The first band at $329 \mathrm{~nm}$ corresponds to pure HOMO- $\rightarrow$ LUMO +2 and $\mathrm{HOMO} \rightarrow \mathrm{LUMO}+1$ transition. The bands at $295 \mathrm{~nm}$ and $255 \mathrm{~nm}$ correspond to one-electron excitations from HOMO-4 to $\mathrm{LUMO} / \mathrm{LUMO}+1$ and $\mathrm{LUMO}+2$. The band predicted at $248 \mathrm{~nm}$ and $231 \mathrm{~nm}$ stems from the HOMO-6 $\rightarrow$ LUMO transition. The most intense band at $239 \mathrm{~nm}$ results from HOMO$5 \rightarrow$ LUMO+2 excitation. Finally, transitions to the LUMO from the HOMO-7 and HOMO-8 are mostly responsible for the bands at $228 \mathrm{~nm}$ and $225 \mathrm{~nm}$ and $215 \mathrm{~nm}$, respectively. The overall good agreement between the calculated spectrum of $\mathrm{TcO}_{3}(\mathrm{OH})\left(\mathrm{H}_{2} \mathrm{O}\right)_{2}$ and the experimental spectrum confirms that $\mathrm{TcO}_{3}(\mathrm{OH})\left(\mathrm{H}_{2} \mathrm{O}\right)_{2}$ is likely the species formed after dilution of $\mathrm{KTcO}_{4}$ in $12 \mathrm{M} \mathrm{H}_{2} \mathrm{SO}_{4}$.

In summary, the speciation of heptvalent technetium has been investigated in sulfuric acid. In $12 \mathrm{M} \mathrm{H}_{2} \mathrm{SO}_{4}$, a yellow solution is observed, and its ${ }^{99} \mathrm{Tc} \mathrm{NMR}$ spectrum is consistent with a heptavalent complex. The yellow solution was further characterized by EXAFS spectroscopy, and results are consistent with the formation of $\mathrm{TcO}_{3}(\mathrm{OH})\left(\mathrm{H}_{2} \mathrm{O}\right)_{2}$. No technetium heptoxide or sulfato- complexes were detected in these conditions. The molecular structure of $\mathrm{TcO}_{3}(\mathrm{OH})\left(\mathrm{H}_{2} \mathrm{O}\right)_{2}$ has been optimized by DFT techniques, and the structural parameters are well in accordance with those found by XAFS spectroscopy. 
The experimental electronic spectra exhibit ligand-to-metal charge transfer transitions that have been assigned using TDDFT methods. Calculations demonstrate the theoretical electronic spectrum of $\mathrm{TcO}_{3}(\mathrm{OH})\left(\mathrm{H}_{2} \mathrm{O}\right)_{2}$ to be in very good agreement with the experimental one. Recent experiments in $12 \mathrm{M} \mathrm{H}_{2} \mathrm{SO}_{4}$ show the yellow solution to be very reactive in presence of reducing agents presumably forming low valent $\mathrm{Tc}$ species. Current spectroscopic works focus on the speciation of these species.

Acknowledgments. The authors thank Mr. Tom O'Dou for outstanding health physics support. Funding for this research was provided by a subcontract through Battelle 0089445 from the US Department of Energy, agreement no.: DE-AC07-05ID14517. Use of the Advanced Photon Source was supported by the U. S. Department of Energy, Office of Science, Office of Basic Energy Sciences, under Contract No. DE-AC02-06CH11357. Part of this work was supported by the U. S. Department of Energy, Office of Science, Office of Basic Energy Sciences, under Contract No. DE-AC02-05CH11231.

\section{Notes and references.}

a Department of Chemistry, University of Nevada Las Vegas, Las Vegas, NV 89154, USA. E-mail: poineauf@unlv.nevada.edu

$\dagger \quad$ Electronic Supplementary Information (ESI) available: Additional details on XAFS experiment and computational method. XANES spectra of the yellow solution, and simulated EXAFS spectra of $\mathrm{Tc}_{2} \mathrm{O}_{7}$ and $\mathrm{TcO}_{2}\left(\mathrm{SO}_{4}\right)_{3}$. Transition energies and oscillator strength for $\mathrm{TcO}_{3}(\mathrm{OH})\left(\mathrm{H}_{2} \mathrm{O}\right)_{2}$ computed using TD-DFT.

1. Bui, C. T.; Rees, K.; Cotton, R. G. H. Nucleosides, Nucleotides \& Nucleic Acids 2003, 22, 1835.

2. K. Schwochau, Technetium: Chemistry and Radiopharmaceutical Applications; WileyVCH: Weinheim, Germany, 2000.

3. Romao, C. C.; Kuehn, F. E.; Herrmann, W. A. Chemical Reviews 1997, 97, 3197.

4. Rudakov, E. S.; Lobachev, V. L. Russian Chemical Bulletin 2000, 49, 761.

5. Tooyama, Y; Braband, H; Spingler, B; Abram, U; Alberto, R. Inorg. Chem. 2008, 47, 257.

6. de Zoubov, N.; Pourbaix, M. CEBELCOR (Centre belge etude corrosion), Rappt. 1957, No. 51 1-14.

7. Engelbrecht, A; Grosse, A V. J. Am. Chem. Soc., 1954, 76, 2042.

8. Briggs, T S. J. Inorg. Nucl. Chem., 1968, 30, 2866. 
9 Thomas, R. W.; Heeg, M. J.; Elder, R. C.; Deutsch, E. Inorg. Chem., 1985, 24, 1472.

10. Grove, D. E.; Johnson, N. Peter; W., G. Inorg. Chem., 1969, 8, 1196.

11. Alberto, R. Technetium. In Comprehensive Coordination Chemistry. II; McCleverty, J. A., Mayer, T. J., Eds.; Elsevier: Amsterdam, The .Netherlands, 2003; Vol. 5, p 136.

12. Stokes, Jimmy C.; Lockhart, William L. Chemistry,1978, 51, 10.

13. Senderens, J. B. Compt. rend., 1923, 176, 813.

14. Royer, D. J. J. Inorg. Nucl. Chem., 1961, 17, 159.

15. Gillespie, R. J.; Kapoor, R. Canadian Journal of Chemistry. 1987, 65, 2665.

16. Simon, A; Dronskowski, R; Krebs, B; Hettich, B. Angew. Chem., 1987, 99, 160.

17. Bardin, V. A.; Petrov, K. I.; Bol'shakov, K. A. Zhurnal Neorganicheskoi Khimii 1966, 11, 2101.

18. Rulfs, C. L.; Pacer, R. A.; Hirsch, R. F. J. Inorg. Nucl. Chem., 1967, 29, 681.

19. Walrafen, G. E.; Yang, W.-H.; Chu, Y. C.; Hokmabadi, M. S. J. Solution Chemistry 2000, 29, 905.

20. Mikhalev, V. A. Radiochemistry 2005, 47, 319.

21. Braband, H; Tooyama, Y; Fox, T; Alberto, R. Chemistry--A European Journal 2009, 15, 633.

22 a,b,c,d. J. Am. Chem. Soc. 1982, 104, 5303; Inorg. Chim. Acta. 1989, 161, 39; Inorg. Chem. 1992, 31, 1976; Inorg Chem., 2006, 45, 6589].

23. Spitsyn, V. I.; Tarasov, V.P.; Guerman, K. E.; Petruchin, S.A.; Kuzina, A.F.; Kryutchkov, S.V. Dolk. Akak. Nauk. SSSR. 1986, 290, 1411.

24. [Inorg. Chem. 1992, 31, 1976]. [Inorg Chem., 2006, 45, 6589]

25 a, b. [Paul, MA; Long, FA Chem. Rev. 1957, 57, 1 and Jorgensen, MJ; Hartter, DR J. Am. Chem. Soc. 1963, 85, 878.]

26. Rard, J.A; Rand, M.H; Anderegg, G; Wanner, H "Chemical Thermodynamics of Technetium," Sandino, MCA; Östhols, E, eds.; Elsevier: Amsterdam, 1999 
27. Boyd, G.E Inorg. Chem., 1978, 17, 1808;

28. Angew. Chem. Ind. Ed., 1968, 7, 295]

29. Supel, J; Hagenbach, A; Abram, U.; Seppelt, K. Zeitschrift fuer Anorganische und Allgemeine Chemie 2008, 634, 646.

30. Weck, P. F.; Kim, E.; Czerwinski, K. R. Chem. Phys. Let.t, 2010, 487, 190.

31. Vichot, L.; Fattahi, M.; Musikas, Cl.; Grambow, B. Radiochim. Acta, 2003, 91, 263.

Table of contents.

The speciation of heptavalent technetium has been performed in sulfuric acid. In $12 \mathrm{M}$ $\mathrm{H}_{2} \mathrm{SO}_{4}$, EXAFS and NMR results are consistent with the formation of the $\mathrm{TcO}_{3} \mathrm{OH}\left(\mathrm{H}_{2} \mathrm{O}\right)_{2}$ species. Molecular structure and electronic spectra of $\mathrm{TcO}_{3} \mathrm{OH}\left(\mathrm{H}_{2} \mathrm{O}\right)_{2}$ were investigated using density functional theory techniques. 


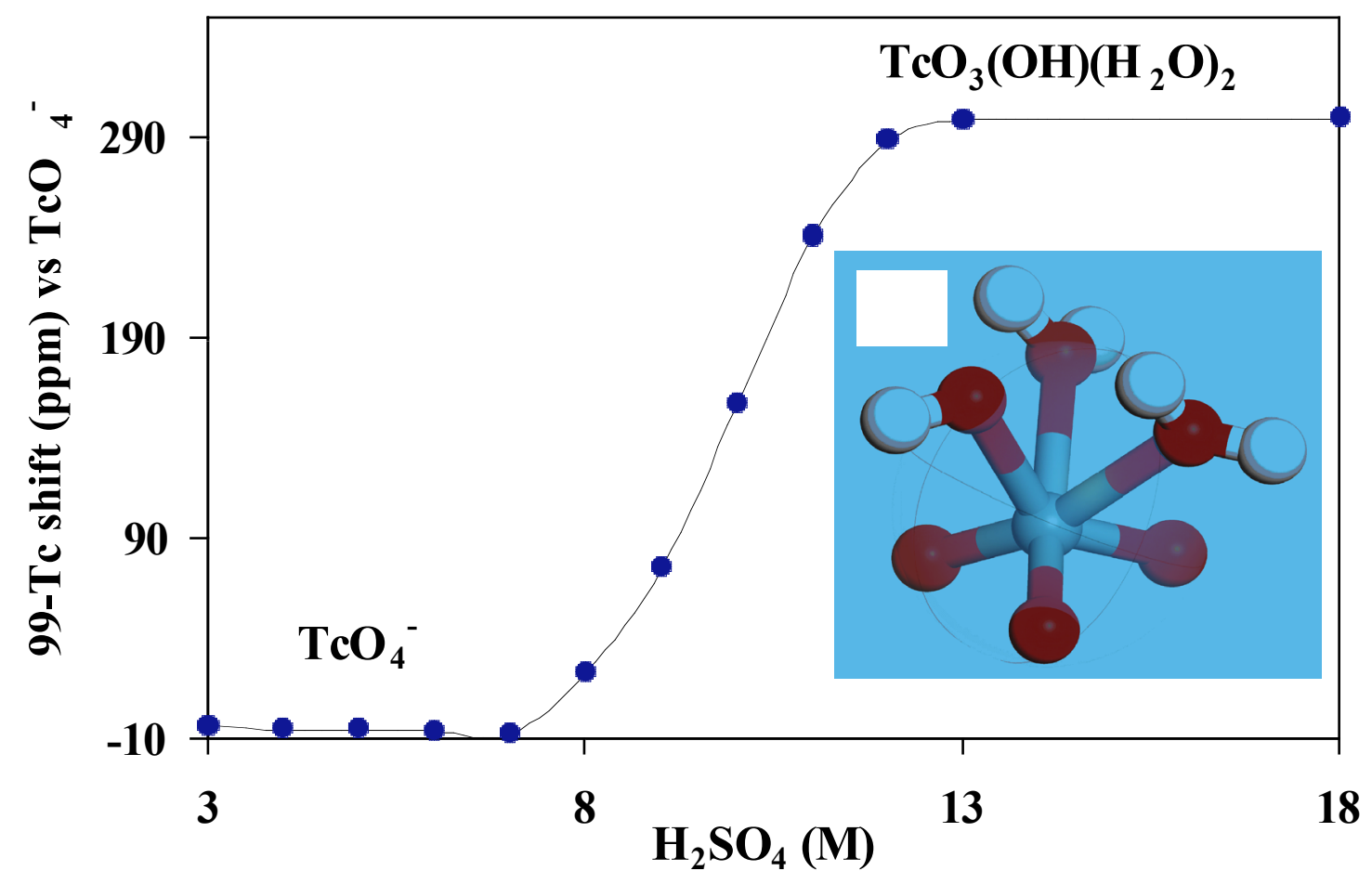

